\section{Corneal densitometry after photorefractive keratectomy, laser-assisted in situ keratomileusis, and small-incision lenticule extraction}

F Poyales, N Garzón, J Mendicute, I Illarramendi, P Caro, O Jáñez, F Argüeso and A López

\begin{abstract}
Purpose The aim of this study was to gain greater insight into the corneal densitometry changes occurring as a result of refractive surgery and to compare these changes across three widely used surgical techniques, namely, photorefractive keratectomy (PRK), laser-assisted in situ keratomileusis with a femtosecond laser (LASIK-FS), or ReLEx small-incision lenticule extraction (ReLEx SMILE).

Patients and methods Three hundred and thirty-six patients (184 male and 152 female patients) participated in this study. They were split into three groups according to the refractive surgery technique they had undergone: LASIK-FS (74 patients), PRK (153 patients), and ReLEx SMILE (109 patients). All participants underwent an exhaustive eye examination both before and after surgery. Pre- and postoperative corneal densitometry was measured using an Oculus Pentacam system.

Results The mean postoperative total corneal densitometry values were $16.53 \pm 1.94$ for the LASIK-FS group, $15.53 \pm 1.65$ for PRK, and $16.10 \pm 1.54$ for ReLEx SMILE. When corneal densitometry was analyzed for specific corneal areas, the values corresponding to the $0-2,2-6$, and $6-10 \mathrm{~mm}$ annuli were similar across the three surgical techniques. The only region in which differences were found was the peripheral area $(P<0.05)$, but these variations across techniques were not statistically significant. Conclusions Corneal densitometry can be used as an objective metric to assess corneal response to refractive surgery, and to monitor patients over time. Corneal densitometry was
\end{abstract}

not negatively affected by any of the refractive surgical procedures under evaluation.

Eye (2017) 31, 1647-1654; doi:10.1038/eye.2017.107; published online 16 June 2017

\section{Introduction}

The cornea is an ocular tissue made up of different layers, and is characterized by its transparency and its ability to refract light. ${ }^{1}$ Nevertheless, the cornea of the human eye also acts as a mirror that reflects light. ${ }^{2}$ Corneal epithelium is the cornea's outermost layer, and is vulnerable to several types of damage, such as the presence of foreign bodies, poor contact lens adaptation, or as a result of refractive surgery. A damaged ocular surface can lead to ocular infection, neovascularization, scars, and so on, with an increased risk of perforation and even more severe complications. ${ }^{3}$

The particular arrangement, density, and position of corneal fibers lead to its elastic behavior. ${ }^{4}$ When subject to compression or stretching, the cornea reorganizes its layers, increasing in elasticity in order to reach a new equilibrium. ${ }^{5,6}$ Corneal stability relies on different factors, such as intraocular pressure (IOP) or the action of extraocular muscles, ${ }^{7}$ but it can also be affected by other elements, such as refractive surgery. ${ }^{8-10}$ Most refractive surgery procedures modify the biomechanics of the cornea, because of the fact that ablation itself can have an impact upon the cornea's hysteresis response. ${ }^{11}$

Various devices have been developed in the past decades to evaluate corneal damage using objective measurements. For instance, in 1986, Freund et $a l^{12}$ established the direct summation
Innova Ocular, Madrid, Spain

Correspondence: F Poyales, Innova Ocular, C/ Galileo 104, Madrid 28003 Spain Tel: +34915353570. E-mail: ioamadrid@ hotmail.es

Received: 29 September 2016

Accepted in revised form: 27 April 2017

Published online: 16 June 2017 
of fields approach, in which corneal transmittance was estimated by measuring light scattering through each corneal fiber. However, this method was way too complex. In the 1990s, owing to the advent of the Scheimpflug imaging technique, the measurement of corneal light backscattering improved significantly. ${ }^{13}$

This very same Scheimpflug imaging technique is currently used in the Pentacam System (Oculus Optikgeräte $\mathrm{GmbH}$, Wetzlar, Germany) to provide information on corneal densitometry and transparency. Pentacam system is a non-invasive system that outputs numerical values, thereby enabling objective evaluation and comparison of both the particular eye condition under study and the patient's evolution over time. This is particularly useful in diseases such as corneal dystrophies, and in the case of refractive surgery.

Some studies have proposed normalized corneal densitometry values as an indicator of corneal health. ${ }^{14}$ Corneal densitometry studies have been conducted following refractive surgery, such as photoreactive keratectomy $(\mathrm{PRK})^{15}$ or laser in situ keratomileusis (LASIK). ${ }^{16}$ However, the Pentacam System comes with an updated map of corneal densitometry, thus yielding complete and accurate information. Refractive lenticule extraction with small-incision lenticule extraction (ReLEx SMILE) is a novel refractive surgery procedure that has not been extensively studied, although the most recent data suggest that it has a smaller impact upon corneal biomechanics compared to LASIK surgery. ${ }^{17}$

To the best of our knowledge, no previous study found in the literature has ever compared different refractive surgery techniques in terms of its impact upon corneal densitometry. Therefore, the purpose of this study was to gain greater insight into the corneal densitometry changes occurring as a result of refractive surgery and to compare these changes-measured with the Oculus' Pentacam System-across three widely used surgical techniques: namely, PRK, LASIK-FS (LASIK with a femtosecond laser), and SMILE. The secondary goal of this work, where significant intertechnique differences to be found, was to develop an algorithm that would help the surgeon decide, in a case-by-case basis, which is the optimal and most effective surgical technique for each patients, thus making it possible to obtain the best-possible visual-quality results.

\section{Materials and methods}

\section{Participants}

This experimental, prospective study was carried out at the Innova Ocular Group Clinic (Madrid, Spain).

The final number of participants was 336 (184 men and 152 women), with the mean age of $32.43 \pm 6.50$ years. Both eyes were evaluated in 316 patients, and the remaining 20 patients were assessed monocularly. Both eyes were included in the study, as they were found to be highly correlated, and the treatment was the same for both eyes. ${ }^{18}$ In 19 of the 20 patients only one eye was included in the study because of the fact that only one eye was operated, whereas in the remaining patient one eye was excluded as it underwent ReLEx SMILE and part of the lenticule could not be completely extracted in the first surgery. The only exclusion criterion was prior eye surgery (irrespective of the specific surgical approach).

The sample was divided into the following three groups, according to the refractive surgery procedure they underwent: 74 patients (42 men and 32 women) to the LASIK-FS group, 153 patients (86 men and 67 women) to the PRK group, and 109 patients (56 men and 53 women) to the ReLEx SMILE group. The groups were homogeneous in terms of pre-values, with no statistically significant differences. Demographic data are shown in Table 1.

All participants entered the study voluntarily and were free to withdraw with no need to give a reason why. Informed consent was obtained from all patients, and the principles of the Declaration of Helsinki ${ }^{19}$ were followed in all procedures. Each patient received the most appropriate refractive surgery treatment, according to the clinical criteria included in the Innova Ocular Group protocols.

\section{Preoperative measurements}

The preoperative assessment included subjective refraction with and without cycloplegic agents, IOP (Goldman tonometer), binocular examination, ocular dominancy, photopic and mesopic pupillometry, corneal topograph, and corneal densitometry (Oculus Pentacam, Oculus Optikgeräte $\mathrm{GmbH}$ ), corneal aberrometry (Wasca, Carl Zeiss Meditec AG, Jena, Germany), and anterior and posterior pole evaluation.

Corneal densitometry was measured with an Oculus Pentacam (software version 1.20r29). This system relies on a series of 25 images $(1003 \times 520$ pixels $)$ taken over different meridians with a uniform blue light source; the acquisition protocol takes $\sim 2 \mathrm{~s}$ to complete. The value shown on the screen is that area's mean value computed from the different individual meridian-specific values. In the analysis stage, the program automatically locates the corneal apex and analyzes the 12-mm-diameter area around it. The output (resulting corneal densitometry) is given in grayscale units (GSUs). The GSU scale is calibrated by means of a proprietary software, which defines a minimum light scatter of 0 (maximum transparency) and a maximum light scatter of 100 (minimum transparency). For the purpose of local densitometry analysis, preoperative values were considered as baseline values, and the measures were limited to the default 12-mm-diameter area, which was later subdivided into four concentric radial 


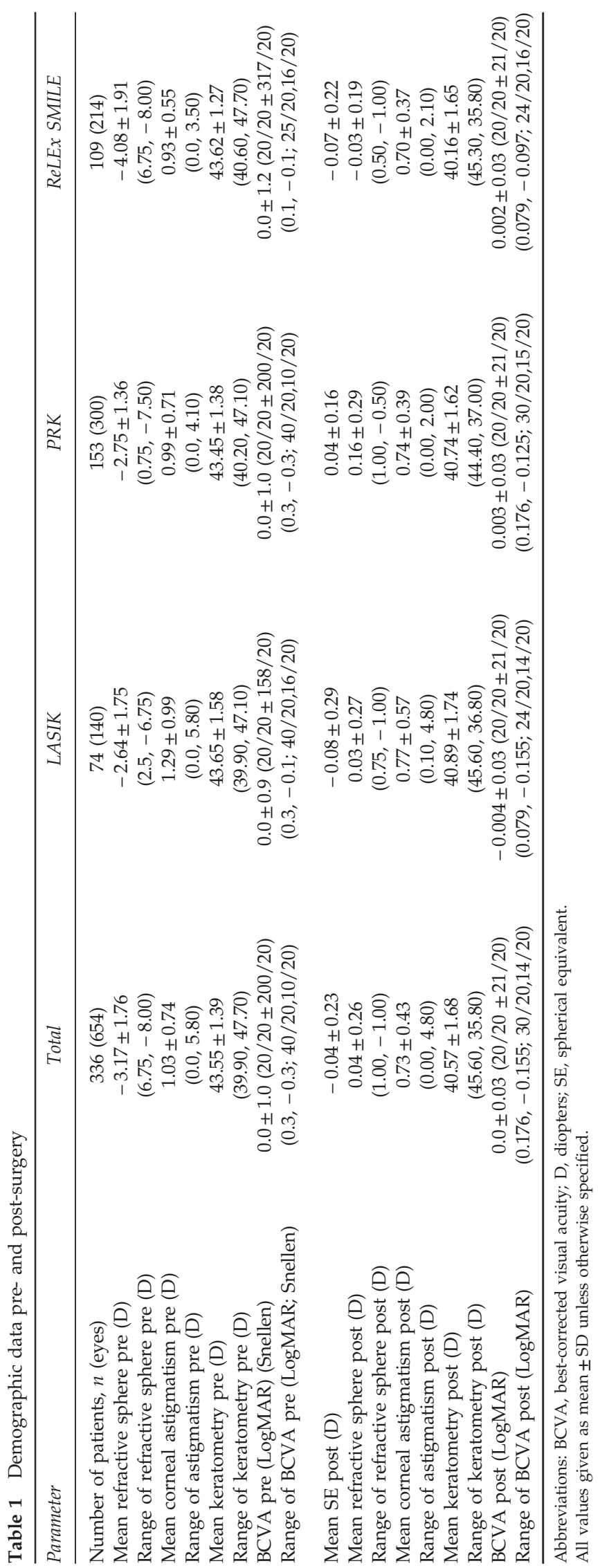



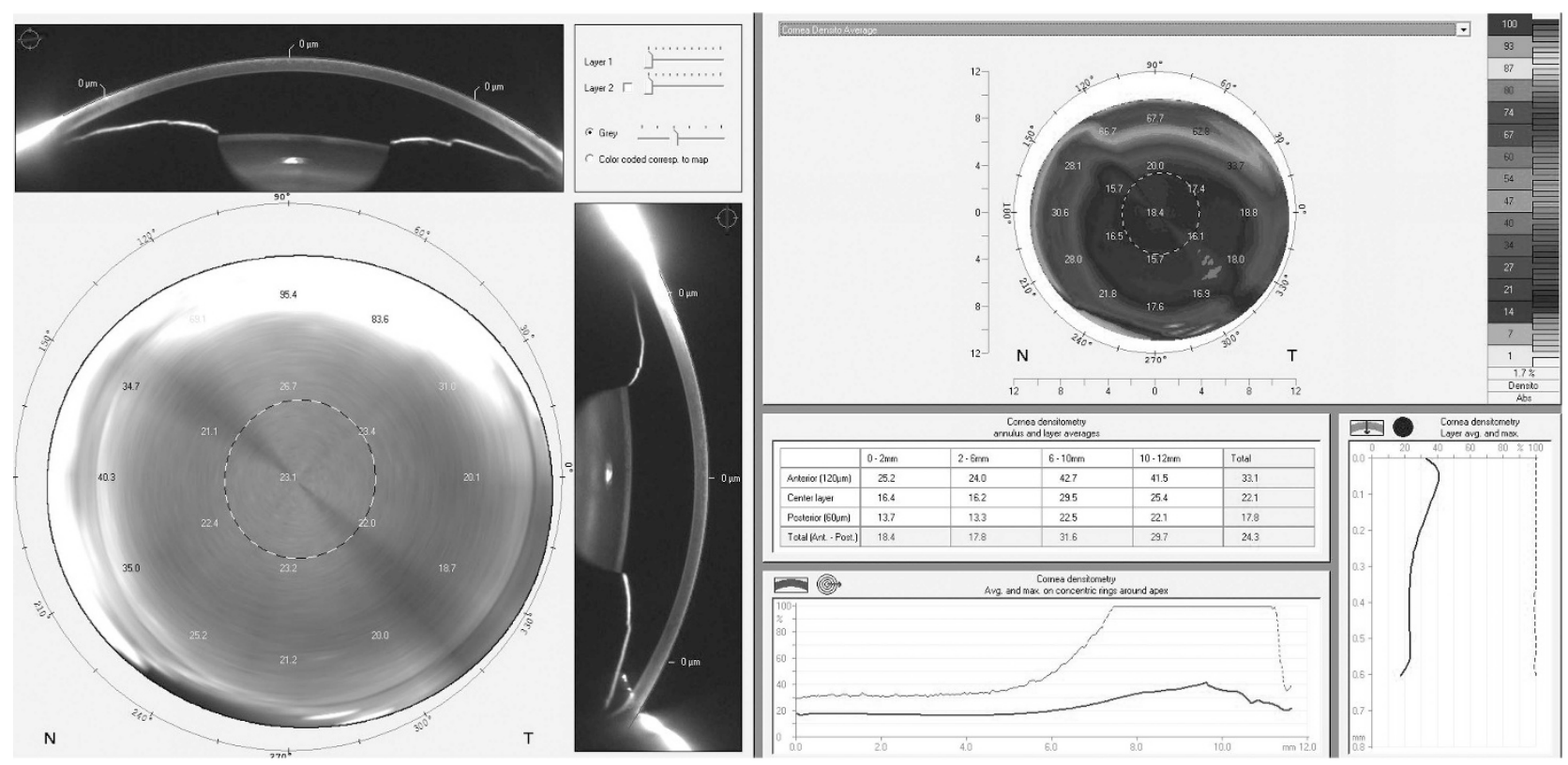

Figure 1 Screen data output of the Scheimpflug optical densitometry assessment. The 12-mm-diameter area is subdivided into four concentric radial zones $(0-2,2-6,6-10$, and $10-12 \mathrm{~mm})$. The output is also subdivided based on corneal depth into anterior (anterior $120 \mu \mathrm{m})$, central, and posterior (the most posterior $60 \mathrm{~lm}$ of the cornea) layers.

zones, all having the apex as center: the central zone $(2 \mathrm{~mm}$ in diameter); the annulus having $2 \mathrm{~mm}$ of internal diameter and $6 \mathrm{~mm}$ of external diameter (referred to as the 2-to-6-mm annulus); a second annulus going from 6 to $10 \mathrm{~mm}$ in diameter (the 6-to-10-mm annulus); and the outermost one: the 10-to-12-mm annulus. ${ }^{20}$ These topographical zones are predefined in the software. Corneal densitometry was also measured at different corneal depths: anterior cornea (the outermost $120 \mu \mathrm{m}$ layer), posterior cornea (the $60 \mu \mathrm{m}$-thick layer that forms the inner surface), and the middle layer lying in between the first two (Figure 1).

\section{Surgical techniques}

All surgeries were performed by four expert ophthalmologists (FP, JM, FA, and PC). For PRK, manual de-epithelialization was performed by applying diluted alcohol on the corneal surface, followed by corneal ablation using the MEL-80 excimer laser platform (Carl Zeiss Meditec AG). Mitomycin C was applied for $20 \mathrm{~s}$ immediately after laser ablation. A therapeutic contact lens was placed after washing the ocular surface. All the patients were advised to wear the contact lens for the first 5 days after surgery. In the case of re-epithelization delay, patients were instructed to keep wearing the contact lens until the end of the process.

As for LASIK-FS, a flap having a thickness of $\sim 100$ or $120 \mu \mathrm{m}$ was created with a Visumax FS femtosecond laser (Carl Zeiss Meditec AG). Corneal carving was performed with a MEL-80 excimer laser, and the flap was then returned to its initial position once the ablation stage was completed.

Finally, for ReLEx SMILE, the lenticule was cut using the same Visumax FS platform used for LASIK-FS, and was then extracted through a $2.0-3.2 \mathrm{~mm}$ peripheral incision.

\section{Postoperative protocol}

The same measurements taken during the preoperative examination (see above) were repeated postoperatively at every visit. In the case of PRK patients, these were scheduled 1 and 3 days after the procedure, plus once a week during the first month after the surgery. In the case of LASIK-FS patients, follow-up visits were scheduled 1 and 3 days postoperatively, as well as the first, second, and fourth weeks after surgery. Finally, ReLEx SMILE patients' follow-up visits were scheduled on days 1, 3, and 10, as well as 1 month after surgery. All patients had a final follow-up visit 3 months after surgery.

For comparison purposes, postoperative corneal densitometry values were defined as those measured at this final follow-up visit, when patients were discharged. These postoperative results were then compared to the ones obtained before surgery (baseline values).

\section{Statistical analysis}

Statistical analysis was performed with the SPSS software (version 22.0, SPSS Inc., Chicago, IL, USA). The values 
obtained and then statistically analyzed are expressed as mean $\pm S D$ values. Bearing in mind the existing correlation between each person's right and left eye corneal densitometry values, eyes of the same subject were treated separately for statistical analysis. Parametric statistical tests were used to compare variables. Pre- and postoperative densitometry values were compared using the Student's $t$-test for paired samples. The Student's $t$-test for independent samples was used to compare values across the different refractive surgery groups. Finally, the potential correlation between corneal densitometry and spherical equivalent was analyzed using Pearson's bivariate regression. Statistical significance was defined as $P<0.05$.

\section{Results}

None of the patients included in this study presented clinically significant haze after surgery. One eye was excluded, as it underwent ReLEx SMILE and part of the lenticule could not be completely extracted in the first surgery.

\section{Corneal densitometry values in each corneal ring zone}

All densitometry values, expressed in GSU, are summarized in Table 2a. Regarding preoperative values, no statistically significant differences were found between the three groups, for any given ring zone under analysis $(P>0.05)$.

On the contrary, when pre- and postoperative values were compared, corneal densitometry had changed significantly (for all ring zones) in the PRK group $(P<0.001)$. However, in the case of LASIK-FS and ReLEx SMILE, significant differences were found only in the peripheral zone, that is, the 10 -to- $12-\mathrm{mm}$ annulus

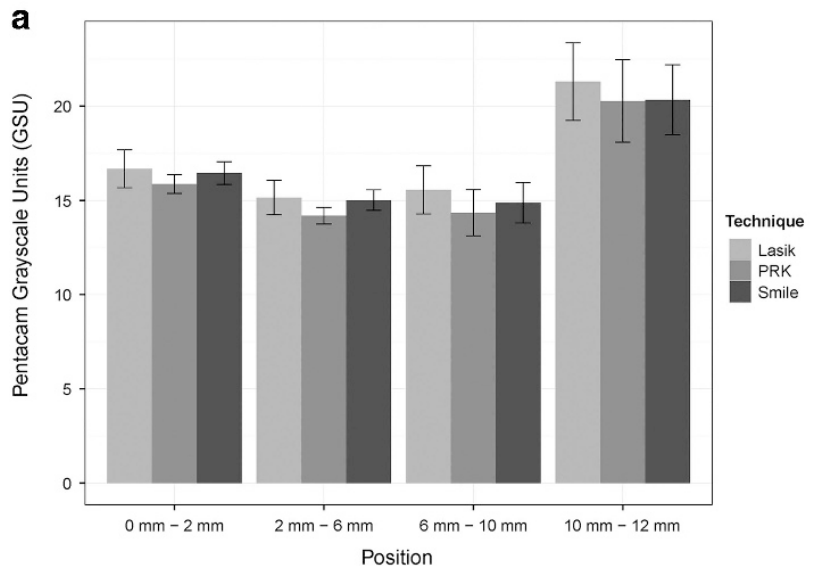

$(P=0.05$ and $P<0.001$, respectively). Figure 2 a shows postoperative densitometry values in a radial segment of the cornea.

\section{Corneal densitometry according to corneal depth values}

Corneal densitometry at different corneal depths was also evaluated. All densitometry values are shown in Table $2 b$.

Table 2a Corneal densitometry values according to the ring area of the cornea (represented in grayscale units, GSU)

\begin{tabular}{lccl}
\hline & LASIK & PRK & \multicolumn{1}{c}{ SMILE } \\
\hline Pre-op 0-2 mm & $16.73 \pm 1.94$ & $16.51 \pm 0.95$ & $16.55 \pm 0.9$ \\
Post-op 0-2 mm & $16.68 \pm 2.02$ & $15.87 \pm 1.00$ & $16.45 \pm 1.20$ \\
Pre-op 2-6 mm & $15.05 \pm 1.66$ & $14.83 \pm 0.86$ & $14.96 \pm 0.85$ \\
Post-op 2-6 mm & $15.15 \pm 1.82$ & $14.19 \pm 0.88$ & $15.01 \pm 1.08$ \\
Pre-op 6-10 mm & $15.43 \pm 2.57$ & $15.04 \pm 2.55$ & $15.00 \pm 2.13$ \\
Post-op 6-10 mm & $15.56 \pm 2.55$ & $14.34 \pm 2.45$ & $14.87 \pm 2.15$ \\
Pre-op 10-12 mm & $22.00 \pm 4.54$ & $21.87 \pm 4.30$ & $21.17 \pm 3.87$ \\
Post-op 10-12 mm & $21.31 \pm 4.11$ & $20.28 \pm 4.38$ & $20.34 \pm 3.72$ \\
\hline
\end{tabular}

Table $2 \mathrm{~b}$ Corneal densitometry values according to the layers of the cornea (represented in grayscale units, GSU)

\begin{tabular}{lccc}
\hline & LASIK & PRK & SMILE \\
\hline Pre-op anterior $120 \mu \mathrm{m}$ & $22.19 \pm 2.67$ & $22.20 \pm 2.49$ & $21.31 \pm 2.09$ \\
Post-op anterior $120 \mu \mathrm{m}$ & $22.14 \pm 2.82$ & $20.19 \pm 2.33$ & $20.98 \pm 2.10$ \\
Pre-op center & $14.74 \pm 1.77$ & $14.43 \pm 1.52$ & $14.55 \pm 1.32$ \\
Post-op center & $14.62 \pm 1.67$ & $14.07 \pm 1.53$ & $14.44 \pm 1.43$ \\
Pre-op posterior $60 \mu \mathrm{m}$ & $12.88 \pm 1.72$ & $12.44 \pm 1.37$ & $13.00 \pm 1.23$ \\
Post-op posterior $60 \mu \mathrm{m}$ & $12.83 \pm 1.71$ & $12.34 \pm 1.46$ & $12.88 \pm 1.38$ \\
Pre-op total & $16.62 \pm 1.97$ & $16.38 \pm 1.67$ & $16.26 \pm 1.50$ \\
Post-op total & $16.53 \pm 1.94$ & $15.53 \pm 1.65$ & $16.10 \pm 1.54$ \\
\hline
\end{tabular}

Corneal densitometry values according to the ring area of the cornea (represented in GSUs; Table 2a) and corneal densitometry values according to the layers of the cornea (represented in GSUs; Table 2b).

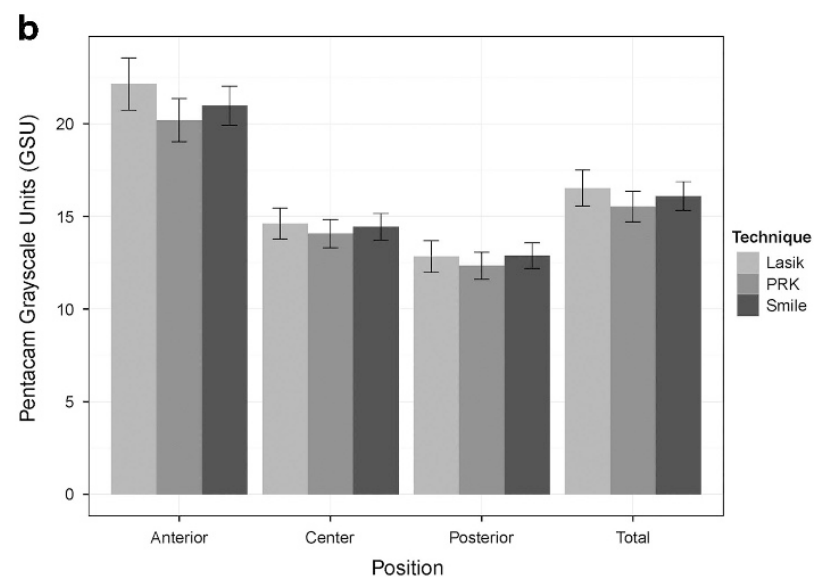

Figure 2 Corneal densitometry measurements according to corneal ring zones postoperative values. There were no statistically significant differences between surgical techniques in any radial segment of the cornea (a). Corneal densitometry measurements according to corneal depth postoperative values. There were no statistically significant differences between surgical techniques in any corneal depth (b). 

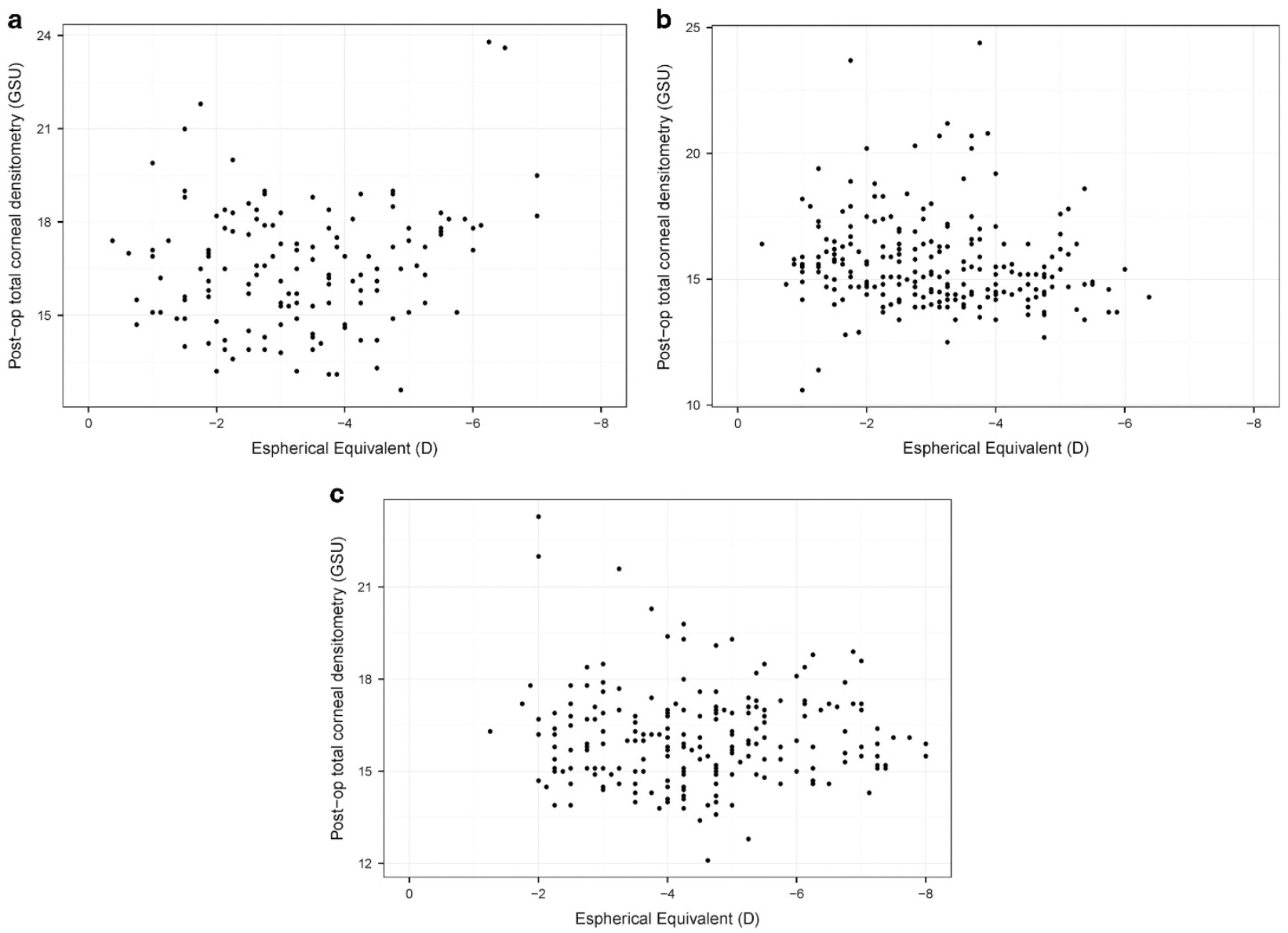

Figure 3 Corneal densitometry dispersion in relation with spherical equivalent and LASIK-FS surgery. Pearson's correlation coefficient: $0.170(P<0.001$; a). Corneal densitometry dispersion in relation with spherical equivalent and PRK surgery. Pearson's correlation coefficient: $0.205(P=0.002$; b). Corneal densitometry dispersion in relation with spherical equivalent and ReLEx SMILE surgery. Pearson's correlation coefficient: $0.258(P=0.001$; $)$.

No statistically significant differences were observed preoperatively between the three groups $(P>0.05)$.

As for the pre-vs-post-surgery comparison, in the ReLEx SMILE group a significant decrease in densitometry values was observed after surgery, but the only differences that were found to be significant were those corresponding to the anterior layer $(P=0.003)$ and to total corneal thickness $(P=0.016)$. No pre-vs-postsurgery differences were found (for any corneal layer) in the LASIK-FS group. On the contrary, in the PRK group there was significant postoperative decrease in densitometry values for all corneal layers $(P<0.001$ for all layers). Figure $2 \mathrm{~b}$ shows postoperative densitometry values at different corneal depths.

\section{Corneal densitometry and spherical equivalent correlation}

Postoperative total corneal densitometry and preoperative spherical equivalent revealed a slight correlation in the PRK group only. The Pearson's correlation coefficient was $r=0.170(P<0.001$; Figure 3a) for the LASIK-FS group, $r=0.218(P=0.002$; Figure $3 b)$ for the PRK group, and $r=0.258(P=0.001$; Figure $3 c)$ in the case of the ReLEx SMILE group.

\section{Discussion}

Corneal densitometry has been studied in some ocular conditions such as bacterial keratitis, ${ }^{21}$ Fuchs' endothelial dystrophy, ${ }^{22}$ and keratoconus, ${ }^{23}$ and following different procedures such as corneal transplant (DALK) ${ }^{24}$ or crosslinking for keratoconus. ${ }^{25}$

This is the first study of corneal densitometry in patients undergoing refractive surgery with either PRK, LASIK-FS, or ReLEx SMILE, using the latest Oculus Pentacam system software. Corneal densitometry can be used as an objective measure of corneal response after refractive surgery, and is valid for monitoring patients over time. This is particularly relevant in post-refractive 
surgery scenarios, due to the potential loss of corneal transparency. In PRK surgery, laser ablation is performed at a plane that corresponds to the corneal stroma's most fibrous layer; therefore, there is higher likelihood of regression and tissue fibrosis than after LASIK surgery. ${ }^{26,27}$ On the contrary, LASIK may cause ectasia $^{28}$ and diffuse lamellar keratitis with ReLEx SMILE. ${ }^{29}$ The monitoring of corneal densitometry values can be helpful in patients having postoperative complications.

Corneal densitometry was highest at the outermost layer-compared to deeper tissue layers-but layerspecific densitometry values did not differ significantly when the three surgical techniques were compared. As for the analysis of the different corneal annuli, the resulting densitometry values revealed significant differences only in the vicinity of the limbal zone. This zone is the area with the poorest repeatability and reproducibility of the measurements. ${ }^{14}$

Previous studies reported corneal densitometry values of $16.76 \pm 1.87 \mathrm{GSU}$, which is similar to our preoperative values: $16.62 \pm 1.97$ for LASIK, $16.38 \pm 1.67$ for PRK, and $16.26 \pm 1.50$ for ReLEx SMILE. ${ }^{15,16,30}$

Previous studies have also evaluated corneal densitometry in PRK and LASIK patients both before and after surgery. ${ }^{14-16}$ As for post-PRK patients, the 3-month postoperative value was $37.81 \mathrm{GSU}$, and the 12 month one was 26.92 GSU, ${ }^{15}$ which is twice the value found in our study. Fares et al ${ }^{16}$ found no significant differences between pre- and postoperative values for overall corneal densitometry following LASIK, and reported corneal densitometry values 12 months after surgery that were slightly lower than our results. These differences might be explained by the different examination protocols, that is, different Oculus Pentacam software, which may have affected the calculated measurements. A possible factor that could explain the differences in densitometry outcomes might be the time elapsed between the surgery and the corneal densitometry assessments. However, in another study in which corneal densitometry was measured in patients undergoing PRK for myopia and hyperopia, changes in corneal densitometry were found only in those patients who developed haze. Those patients who had kept a clear cornea after surgery had the same values as subjects who had not undergone surgery: $29.9 \pm 8.7$ GSU in the clear-cornea myopia group and $25.1 \pm 2.4$ GSU in the non-operated myopia group. ${ }^{30}$

ReLEx SMILE is a novel technique for the treatment of refractive errors, which explains why so few studies have been published so far. With respect to parameters associated with corneal transparency, such as corneal haze or contrast sensitivity, the studies found in the literature have reported that the ReLEx procedure results in better contrast sensitivity than the femtosecond LASIK technique, ${ }^{31,32}$ and less corneal haze than PRK surgery. ${ }^{33}$ This is the first study to evaluate corneal densitometry in ReLEx SMILE patients. The normal pre- and postoperative densitometry values herein reported might be indicative of minimal scarring or haze affecting corneal transparency. The comparison between techniques suggests that total corneal densitometry is not enough to reveal differences among them. The analysis must be performed in a predetermined way, because of the limitations imposed by the Pentacam software, but densitometry evaluation exactly in the interface area in ReLEx SMILE and LASIK surgeries would be interesting, so as to see whether there are significant differences between these techniques and to be able to extrapolate these results to visual-quality analysis.

Although the present study analyzed corneal densitometry parameters in depth in these patients, some limitations apply. We only performed one corneal densitometry measurement on the day the patients were discharged. We believe that more frequent densitometry post-surgery monitoring might be of interest, including it at all postoperative visits within the first year after surgery.

Most studies have used slit lamp observation and subjective assessment to report loss of transparency after refractive surgery. The possibility of assessing changes in corneal transparency non-invasively and objectively could allow better patient management. Densitometry measurement with the Pentacam system maybe a useful and objective tool for evaluating postoperative corneal transparency. ${ }^{21}$ Thus, densitometry measurements will give refractive surgeons an objective measure of the corneal response and haze, allowing these to be monitored over time.

In conclusion, corneal densitometry was not negatively affected by any of the refractive surgical procedures under evaluation, and could become an essential tool in postoperative monitoring protocols.

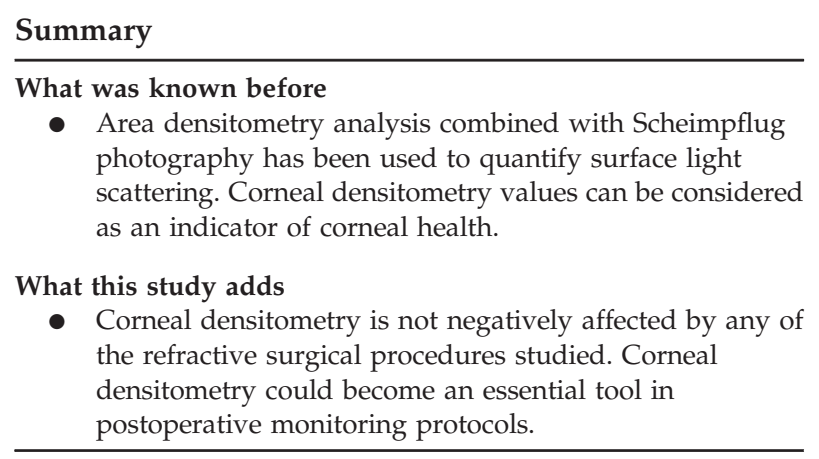

\section{Conflict of interest}

The authors declare no conflict of interest. 


\section{Disclaimer}

The authors do not have any financial interest in any of the materials or instruments used in this study. This study did not receive any funding.

\section{References}

1 Meek KM, Leonard DW, Connon CJ, Dennis S, Khan S. Transparency swelling and scarring in the corneal stroma. Eye (Lond) 2003; 17: 927-936.

2 Nitschke C, Nakazawa A, Takemura H. Corneal imaging revisited: an overview of corneal reflection analysis and applications. IPSJ Trans Comput Vis Appl 2013; 5: 1-18.

3 Pfister RR. Clinical measures to promote corneal epithelial healing. Acta Ophthalmol Suppl 1992; 202: 73-83.

4 Pinero DP, Alcon N. In vivo characterization of corneal biomechanics. J Cataract Refract Surg 2014; 40: 870-887.

5 Shin TJ, Vito RP, Johnson LW, McCarey BE. The distribution of strain in the human cornea. J Biomech 1997; 30: 497-503.

6 Boote C, Dennis S, Newton RH, Puri H, Meek KM. Collagen fibrils appear more closely packed in the prepupillary cornea: optical and biomechanical implications. Invest Ophthalmol Vis Sci 2003; 44: 2941-2948.

7 Bueno-Gimeno I, Espana-Gregori E, Gene-Sampedro A, Lanzagorta-Aresti A, Pinero-Llorens DP. Relationship among corneal biomechanics, refractive error, and axial length. Optom Vis Sci 2014; 91: 507-513.

8 Roberts C. Biomechanics of the cornea and wavefrontguided laser refractive surgery. J Refract Surg 2002; 18: S589-S592.

9 Chen MC, Lee N, Bourla N, Hamilton DR. Corneal biomechanical measurements before and after laser in situ keratomileusis. J Cataract Refract Surg 2008; 34: 1886-1891.

10 Pedersen IB, Bak-Nielsen S, Vestergaard AH, Ivarsen A, Hjortdal J. Corneal biomechanical properties after LASIK, ReLEx flex, and ReLEx smile by Scheimpflug-based dynamic tonometry. Graefes Arch Clin Exp Ophthalmol 2014; 252: 1329-1335.

11 Roberts C. The cornea is not a piece of plastic. J Refract Surg 2000; 16: 407-413.

12 Freund DE, McCally RL, Farrell RA. Direct summation of fields for light scattering by fibrils with applications to normal corneas. Appl Opt 1986; 25: 2739.

13 Smith GT, Brown NA, Shun-Shin GA. Light scatter from the central human cornea. Eye 1990; 4, Pt 4 584-588.

14 Ni Dhubhghaill S, Rozema JJ, Jongenelen S, Ruiz Hidalgo I, Zakaria N, Tassignon MJ. Normative values for corneal densitometry analysis by Scheimpflug optical assessment. Invest Ophthalmol Vis Sci 2014; 55: 162-168.

15 Cennamo G, Forte R, Aufiero B, La Rana A. Computerized Scheimpflug densitometry as a measure of corneal optical density after excimer laser refractive surgery in myopic eyes. J Cataract Refract Surg 2011; 37: 1502-1506.

16 Fares U, Otri AM, Al-Aqaba MA, Faraj L, Dua HS. Wavefront-optimized excimer laser in situ keratomileusis for myopia and myopic astigmatism: refractive outcomes and corneal densitometry. J Cataract Refract Surg 2012; 38: 2131-2138.
17 Wu D, Wang Y, Zhang L, Wei S, Tang X. Corneal biomechanical effects: small-incision lenticule extraction versus femtosecond laser-assisted laser in situ keratomileusis. J Cataract Refract Surg 2014; 40: 954-962.

18 Karakosta A, Vassilaki M, Plainis S, Elfadl NH, Tsilimbaris M, Moschandreas J. Choice of analytic approach for eye-specific outcomes: one eye or two? Am J Ophthalmol 2012; 153: 571-579 e1.

19 Tognoni G. [The new Helsinki declaration]. Assist Inferm Ric 2009; 28(1): 49-51.

20 Savini G, Huang J, Lombardo M, Serrao S, SchianoLomoriello D, Venanzio $S$ et al. Objective monitoring of corneal backward light scattering after femtosecond laserassisted LASIK. J Refract Surg 2016; 32: 20-25.

21 Otri AM, Fares U, Al-Aqaba MA, Dua HS. Corneal densitometry as an indicator of corneal health. Ophthalmology 2012; 119: 501-508.

22 Alnawaiseh M, Rosentreter A, Prokosch V, Eveslage M, Eter N, Zumhagen L. Changes in corneal densitometry in patients with fuchs endothelial dystrophy after endothelial keratoplasty. Curr Eye Res 2016; 1-5.

23 Lopes B, Ramos I, Ambrosio R Jr. Corneal densitometry in keratoconus. Cornea 2014; 33: 1282-1286.

24 Bhatt UK, Fares U, Rahman I, Said DG, Maharajan SV, Dua HS. Outcomes of deep anterior lamellar keratoplasty following successful and failed 'big bubble'. Br J Ophthalmol 2012; 96: 564-569.

25 Pircher N, Pachala M, Prager F, Pieh S, Schmidinger G. Changes in straylight and densitometry values after corneal collagen crosslinking. J Cataract Refract Surg 2015; 41: 1038-1043.

26 Wilson SE. Analysis of the keratocyte apoptosis, keratocyte proliferation, and myofibroblast transformation responses after photorefractive keratectomy and laser in situ keratomileusis. Trans Am Ophthalmol Soc 2002; 100: 411-433.

27 Netto MV, Ambrosio R Jr., Chalita MR, Krueger RR, Wilson SE. [Corneal wound healing response following different modalities of refractive surgical procedures]. Arq Bras Oftalmol 2005; 68: 140-149.

28 Javadi MA, Mohammadpour M, Rabei HM. Keratectasia after LASIK but not after PRK in one patient. J Cataract Refract Surg 2006; 22: 817-820.

29 Zhao J, He L, Yao P, Shen Y, Zhou Z, Miao H et al. Diffuse lamellar keratitis after small-incision lenticule extraction. J Cataract Refract Surg 2015; 41: 400-407.

30 Takacs AI, Mihaltz K, Nagy ZZ. Corneal density with the Pentacam after photorefractive keratectomy. J Refract Surg 2011; 27: 269-277.

31 Ganesh S, Gupta R. Comparison of visual and refractive outcomes following femtosecond laser- assisted lasik with smile in patients with myopia or myopic astigmatism. J Refract Surg 2014; 30: 590-596.

32 Gertnere J, Solomatin I, Sekundo W. Refractive lenticule extraction (ReLEx flex) and wavefront-optimized FemtoLASIK: comparison of contrast sensitivity and high-order aberrations at 1 year. Graefes Arch Clin Exp Ophthalmol 2013; 251: 1437-1442.

33 Ivarsen A, Asp S, Hjortdal J. Safety and complications of more than 1500 small-incision lenticule extraction procedures. Ophthalmology 2014; 121: 822-828. 